\title{
CONTEXTO SÓCIO HISTÓRICO DE CONSTRUÇÃO DOS CONCEITOS DE QUALIDADE E QUALIDADE DA EDUCAÇÃO: DA PERSPECTIVA EMPRESARIAL A EDUCACIONAL COMO DIREITO DE TODOS
}

\author{
Wanessa Maria de Lima ${ }^{1}$ \\ Joseana Maria Saraiva $^{2}$
}

\section{Resumo}

O estudo trata do contexto sócio histórico e cultural de construção do conceito de qualidade, sobremodo, de qualidade da educação, apresentado por estudiosos da área, clássicos e contemporâneos, a partir de diferentes perspectivas e situações. Trata-se de uma pesquisa bibliográfica, através da qual se buscou referências em livros, artigos publicados em periódicos científicos e em dissertações e teses que tratam dos respectivos fenômenos. Priorizou-se a perspectiva histórico crítica, a partir das sociedades ágrafas a contemporânea. O percurso percorrido pelo debate mostrou que o conceito de qualidade e de qualidade da educação, é histórico, socialmente construído e, portanto, reflete em cada conjuntura um significado, imbuído de contradições e controvérsias.

Palavras-chave Qualidade. Qualidade da Educação. Contexto Sócio Histórico

\begin{abstract}
The study deals with the socio-historical and cultural context of the construction of the concept of quality, over-quality and quality of education presented by classical and contemporary scholars from different perspectives and situations. It is a bibliographical research, through which references were sought in books, articles published in scientific journals and in dissertations and theses dealing with the respective phenomena. The critical historical perspective was prioritized, from the contemporary to the staple societies. The course of the debate has shown that the concept of quality and quality of education is historical, socially constructed and therefore reflects in each conjuncture a meaning, imbued with contradictions and controversies.
\end{abstract}

Keywords Quality. Quality of Education. Historical Partner Context.

\section{INTRODUÇÃO}

A qualidade e a qualidade da educação são categorias que tem desempenhado um papel relevante na história das sociedades desde épocas muito remotas. São, portanto, condições históricas e socialmente construídas, que vem se alterando no tempo e no espaço

\footnotetext{
1 Professora de Educação Infantil e do Ensino Fundamental da Prefeitura de Vitória de Santo Antão-PE. Economista Doméstica e Pedagoga. Mestra em Consumo, Cotidiano e Desenvolvimento Social / UFRPE. Membro do Núcleo de Estudos e Pesquisa em Políticas Públicas para Infância e Adolescência/ NEPIAD/UFRPE. Endereço: Rua Manoel de Medeiros, s/n - Dois Irmãos, Recife - PE, CEP. 52171-900, Brasil. Telefone: (81) 99600-6468. Email: wanessaefed@yahoo.com.br

${ }^{2}$ Professora Adjunta do Departamento de Ciências Domésticas da Universidade Federal Rural de Pernambuco (DCD-UFRPE). Professora do Programa de Pós-graduação em Consumo, Cotidiano e Desenvolvimento Social (PGCDS/ UFRPE). Economista Doméstica. Mestra em Nutrição (1999) e Doutora (2009) em Serviço Social. Coordenadora do Núcleo de Estudos e Pesquisa em Políticas Públicas para Infância e Adolescência / UFRPE. Endereço: Rua Manoel de Medeiros, s/n - Dois Irmãos, Recife - PE, CEP. 52171-900, Brasil. Telefone: (81) 3320-6535. Email: joseanasaraiva@yahoo.com.br.
}

Revista de Administração Educacional, Recife, V. 1 . Nº 1 . 2017 jan./jun. 2017 p.52-66 
como consequência das novas exigências da sociedade de consumo capitalista, refletindo em cada conjuntura significados e tendências inerentes a cada época. Isto significa assegurar que, tratar de qualidade, sobretudo, de qualidade da educação na sociedade de consumo capitalista contemporânea, é totalmente diferente de abordar estas categorias nos primórdios da humanidade, ou nas sociedades ágrafas.

Nesse sentido, para compreender o percurso seguido pelo debate da qualidade e da qualidade da educação, torna-se importante delimitar no tempo e no espaço a evolução desses conceitos, considerando que conforme as demandas e as exigências sociais de cada período da história, estes conceitos, na sua constituição, vêm evoluindo e apresentando traços distintos.

Pensar as categorias qualidade e qualidade da educação sem ser ancorada na história é um discurso sem fundamentos, é não valorizar e fragmentar a construção do conhecimento. Assim sendo, para compreender essas categorias faz-se necessário buscar as construções históricas, culturais e sociais, que conformam uma relação direta com elementos subjetivos e objetivos.

Tal como acontece com a categoria de estudo qualidade da educação, também, a categoria qualidade não é um fenômeno da contemporaneidade. A princípio, a preocupação com a qualidade sempre esteve presente na vida do ser humano, considerando as várias dimensões que a compreende. Segundo vários estudiosos, desde épocas muito remotas, o ser humano já se deparava com a busca da qualidade como uma condição necessária a sobrevivência. Nas primeiras formas de sociedade, o ser humano, preocupou-se com a seleção dos alimentos que extraía da natureza. Com o desenvolvimento da agricultura, o ser humano passou a se preocupar com a qualidade daquilo que plantava, tendo em vista a colheita e consumir produtos em bom estado de conservação, excluindo aqueles inapropriados. Por uma questão de segurança e sobrevivência, preocupava-se também com a qualidade das pedras selecionadas para a fabricação de armas e ferramentas para o trabalho cotidiano.

Nesse processo, considerando as melhorias que ocorreram há milênios e que contribuíram inquestionavelmente para a evolução da humanidade, os seres humanos das sociedades ágrafas podem não ter pensado em qualidade na mesma perspectiva como se pensa na sociedade contemporânea - como uma condição necessária e direito de todos - mas, com certeza já existia como elemento que dá qualificação e que evitou graves problemas.

Para se ter ideia, na Idade Antiga, Aristóteles, fundamentado no entendimento que tinha acerca do fenômeno qualidade, apresentado como - as virtudes (por exemplo, justiça; domínio próprio; moral como um atributo positivo de um indivíduo; disposição de um

Revista de Administração Educacional, Recife, V. 1 . № 1 . 2017 jan./jun. 2017 p.52-66 
individuo para praticar o bem), as formas (por exemplo, triangular, redonda), as coisas que nos tornam capazes ou incapazes de fazer algo (por exemplo força muscular, cegueira) e quaisquer características que somos capazes de perceber (por exemplo, doçura, clareza), sobremodo, o conhecimento de algo, é classificado como uma qualidade - trata desse fenômeno dando ênfase a primeira ideia de escola de Estado, preocupado com o bem comum das polis (cidade-Estado). Para esse filósofo, a educação deveria ser pública e de qualidade, estar a cargo do Estado e ser igual para todos os cidadãos.

Essa indicação definidora da qualidade, e da qualidade da educação ainda que ela mesma se preste a muitas outras determinações, vai desvelar aspectos da qualidade ou da sua falta na educação escolar, fenômeno de interesse deste estudo. Essas reflexões iniciais servirão, pois, de ponto de partida para o estudo desses fenômenos de forma histórico-crítica nos períodos subsequentes em que se desenvolvem.

$\mathrm{Na}$ perspectiva de compreender a multiplicidade de interpretações e os novos significados acerca destas categorias, este estudo tem como objetivo apreender as construções históricas, sociais e culturais, destacando aspectos essenciais que as determinam e as conformam na sociedade de consumo contemporânea.

Trata-se de uma pesquisa teórica de abordagem qualitativa, de caráter explicativo. Para tanto, realizou-se uma revisão bibliográfica utilizando as contribuições e a atenção que vem sendo dada por estudiosos de diversas áreas do conhecimento científico aos fenômenos em questão.

Ressalta-se a importância do debate acadêmico acerca das referidas categorias, na perspectiva de assegurar a relação qualidade e qualidade da educação como direito de todos e não de poucos, portanto, dever do Estado. Inicia-se com uma análise das construções históricas, culturais e sociais acerca das categorias de estudo qualidade e qualidade da educação na Pré-história, na Antiguidade, na Idade Média e na Modernidade, segue-se a explicação de forma mais aprofundada na sociedade contemporânea.

Finalmente, as autoras apresentam considerações acerca dos resultados dos debates em torno da concepção de qualidade e qualidade da educação e conduzem sugestões para a produção de novos conhecimentos acerca das categorias de estudo consideradas.

Contexto sócio histórico e cultural da construção do conceito de qualidade e de qualidade da educação: da perspectiva empresarial a educacional como direito de todos e não de poucos

Revista de Administração Educacional, Recife, V. 1 . № 1 . 2017 jan./jun. 2017 p.52-66 
O percurso percorrido pelo debate mostra que o conceito de qualidade e de qualidade da educação é histórico, socialmente construído e, portanto, reflete em cada conjuntura um significado, existente na sociedade. Nesse passeio, verifica-se que na pré-história a discussão sobre este fenômeno é centrada nos processos de sobrevivência do ser humano quando este se depara com a necessidade de consumo básico.

$\mathrm{Na}$ antiguidade, Aristóteles trata desse fenômeno dando ênfase a primeira ideia de escola de Estado, preocupado com o bem comum das polis (cidade-Estado). Para esse filósofo, a educação deveria ser pública e de qualidade, estar a cargo do Estado e ser igual para todos os cidadãos. Na Idade Média, o foco vai remeter o conceito de qualidade a educação profissional que vai ao encontro das necessidades da sociedade de consumo mercantilista emergente.

Na modernidade, a importância de considerar a qualidade na educação fundamenta-se, inicialmente, no pensamento de Comenius, que revela uma preocupação com a qualidade na educação, desde a didática das línguas e das ciências até a organização das escolas, com o plano ambicioso de uma profunda reforma de todas as escolas. Corroborando as ideias de Comenius, os marxistas, a partir da dialética, chamam a atenção para a passagem da quantidade para a qualidade, através da qual as mudanças em um ser, especialmente na sua quantidade ou na sua forma, podem produzir um salto de qualidade que supera o anterior, distinguindo-o mediante um diferenciador, a qualidade.

Na Idade Contemporânea, mais especificamente a partir da década de 1940, o conceito de qualidade, segundo Herédia (1997, p. 98), passa a ser amplamente discutido e difundido, sobretudo na perspectiva da Qualidade Total, em nível mundial. Através das empresas japonesas, este conceito passa a ser incorporado em programas técnicos de produção, controle e gestão, para designar a busca de um padrão desejado para os produtos e serviços prestados à época.

O conceito de qualidade total é uma filosofia de administração dos negócios das empresas visando o atendimento pleno das necessidades de um cliente. Nesses termos, seu objetivo compreende a ampliação não apenas de todos os escalões de uma organização, mas, também, da organização estendida - seus fornecedores, distribuidores e demais parceiros de negócios (HERÉDIA, 1997, p. 98).

A concepção prevalente dessa filosofia é que Qualidade Total é uma ferramenta gerencial na condução dos negócios de uma empresa que deve ser aplicada a todas as áreas e 
níveis, devendo sempre começar do topo, com o comprometimento total da alta administração (HARGRAVES; et.al., 2007, p. 6). Segundo Chiavenato (2003, p.153) o significado de qualidade total compreende o conceito de qualidade para todos os níveis organizacionais, desde o pessoal do escritório e do chão de fábrica até a alta cúpula, em um envolvimento total. Nestes termos o gerenciamento da Qualidade Total é um conceito de controle que atribui as pessoas, e não somente aos gerentes e dirigentes, a responsabilidade de padrões de qualidade.

Assim sendo, a Qualidade Total está baseada no empoderamento das pessoas, o que proporciona aos funcionários autoridade para tomar decisões que, normalmente, eram responsabilidade dos gerentes. Assim, os funcionários podem resolver questões sem terem que consultar seus gerentes a todo momento, poupando tempo e agilizando a resolução de problemas, beneficiando, sobretudo, tanto as empresas quanto os clientes, que têm suas necessidades atendidas em pouco tempo. Nessa direção, a empresa economiza tempo, dinheiro, recursos materiais, agiliza o processo de produção de bens (produtos) e de serviços e proporciona a satisfação dos seus clientes (MAXIMIANO, 1995, p.76).

Com o término da Segunda Guerra Mundial, principalmente no final da década de 1950, o recrudescimento da Guerra Fria entre Oriente e Ocidente fez com que a questão "qualidade" ganhasse uma importância vital, uma vez que os problemas da falta da qualidade eram causados, em $80 \%$ dos casos, por falhas gerenciais e não por falhas técnicas (AILDEFONSO, 2006, p.8). As empresas sempre se preocuparam com a qualidade no "chão de fábrica”, esquecendo-se de que os grandes problemas surgiam das falhas de comunicação entre os diversos órgãos da empresa e entre os diversos níveis hierárquicos.

A garantia da qualidade assegura ao cliente que o fornecedor tem a capacidade de atender a todos os requisitos técnicos e organizacionais exigidos nas normas e nos contratos de fornecimento, baseado na aplicação conjunta da teoria da Administração da Qualidade e dos princípios do Controle Total da Qualidade. Para tanto, para se conseguir a verdadeira garantia de qualidade de um produto, o controle deve começar pelo seu projeto, estender-se à sua entrega e terminar quando o usuário demonstrar satisfação com o uso do produto.

Em síntese, provê ao fornecedor a confiança de que sua empresa poderá atender a todos os requisitos do contrato e das normas aplicáveis. A garantia da qualidade está ligada, portanto, a uma transação comercial entre duas partes. É uma exigência do cliente e, sendo uma medida imposta, sofre restrições quanto ao grau de envolvimento do fornecedor e de seus funcionários.

Revista de Administração Educacional, Recife, V. 1 . № 1 . 2017 jan./jun. 2017 p.52-66 
Assim, os órgãos de compra do governo dos Estados Unidos e demais países da Organização do Tratado do Atlântico Norte (OTAN) passaram a exigir dos seus fornecedores a implementação de Programas de Garantia da Qualidade, minimizando dessa forma os problemas evidenciados pela falta da qualidade. A Garantia da Qualidade vai assegurar ao cliente que o fornecedor tem a capacidade de atender a todos os requisitos técnicos e organizacionais exigidos nas normas e nos contratos de fornecimento.

Na década de 1960, o conceito de Qualidade Total foi amplamente difundido em nível mundial, sendo incorporado em programas técnicos de produção, controle e gestão empresarial. Segundo Alves (2012, p.2), este conceito passa a ser utilizado não apenas no contexto das organizações privadas, sendo apreendido também pelos mais diversos setores da sociedade, inclusive por parte dos educadores, tanto de escolas públicas como particulares. Este novo paradigma trouxe dentro do seu arcabouço teórico novos padrões de produção, de consumo, de conhecimento, formas culturais e práticas políticas que, progressivamente, foram sendo transportadas para o campo da educação e mostra-se hoje como um discurso oficial para as políticas públicas.

Para Gentili e Silva (2015, p. 98), o conceito de qualidade no campo da educação foi, inicialmente, tão somente centrado em recursos humanos e materiais dos sistemas escolares ou suas partes componentes: proporção do produto interno bruto ou do gasto público dedicado a educação, custo por aluno, número de alunos por professor, duração da formação e nível salarial dos professores. Este enfoque vai atender a perspectiva de medir a qualidade total dos serviços públicos, supondo que mais custos ou mais recursos, materiais ou humanos, por usuário era igual a maior qualidade na educação, perspectiva que se fundamenta na concepção de administração escolar multilateral dos organismos internacionais.

Posteriormente, o foco da atenção do conceito de qualidade empresarial se desloca dos recursos para a eficácia do processo, significando conseguir o máximo resultado com o mínimo custo. Pouco tempo depois, a Americana National for Excellence in Education lança o grito de socorro pela palavra de ordem, isto é, "melhoria da qualidade na educação". Segundo Cubberley, citado por Gentili e Silva (2015, p. 99), a escola deveria servir a comunidade, identificando esta com a empresa. Neste sentido, os alunos deveriam ser modelados pela escola de acordo com os desejos das empresas, da mesma forma que estas produziam seus produtos de acordo com os desejos dos consumidores. Nesse conjunto, o processo de trabalho dos professores deveria ser organizado e normalizado da mesma forma dos trabalhadores na indústria. A escola deveria ser avaliada de acordo com a proporção de 
alunos nela matriculados, os dias de frequência no ano e o tempo necessário, por aluno, para realizar um trabalho, inclusive estimar o custo de cada lição por matéria, para suprimir as menos rentáveis.

A retórica da qualidade se impõe rapidamente como senso comum nas burocracias, entre os intelectuais e, mais dramaticamente, em um número nada desprezível daqueles que sofreram e continuam sofrendo as consequências do êxito da implantação e implementação destas práticas conservadoras, fundadas na lógica econômica do capital - os professores, os pais e os alunos.

Neste sentido, a retórica conservadora da qualidade no campo educativo segue uma dinâmica de duplo processo de transposição. A primeira dimensão deste processo remete ao problema do deslocamento da democratização da educação, ao da qualidade. A segunda, à transferência dos conteúdos que caracterizam a discussão sobre qualidade no campo produtivo-empresarial para o campo das políticas educativas e para a análise dos processos pedagógicos (GENTILI; SILVA, 2015, p. 116-117).

Nessa perspectiva, os discursos constituem dimensões anunciativas de um tipo específico de ideologia somente compreensível no contexto da realidade material que a determina. O discurso da qualidade remete diretamente ao plano das práticas materiais nas quais este discurso tem sido lido e entendido. Em outras palavras, a substituição, no campo educacional, do discurso da democratização pela qualidade da educação é a expressão de certas opções políticas de cunho claramente conservador e de sentido que hegemoniza o cenário latino-americano contemporâneo.

Para Zitkoski (1997, p. 84), o que está na raiz das teorias sobre Qualidade Total na educação, de reengenharia do ensino, da eficiência e excelência do ensino, é a razão instrumental, como a positivação da vida, tecnificação do conhecimento, burocratização dos sistemas e atrofiamento das capacidades crítica e criativa do ser humano, indo ao encontro da lógica da nova ordem do sistema capitalista - o neoliberalismo.

Na década de 1970, o debate é marcado pela dualidade qualidade versus quantidade. Num período em que boa parte das redes públicas latino-americanas alcançava percentuais muito pequenos de usuários, o enfoque da quantidade defende a democratização do acesso, a expansão das oportunidades de educação na rede pública para os menos favorecidos. Segundo Carreira (2007, p.20), o enfoque da qualidade era identificado como proposta elitista, qualidade para poucos. Em função do alto nível de repetência nas escolas públicas, nos anos

Revista de Administração Educacional, Recife, V. 1 . № 1 . 2017 jan./jun. 2017 p.52-66 
1980 ganha espaço a discussão acesso versus permanência, relacionando-se qualidade e eficiência ao sistema de indicadores de repetência e rendimento escolar.

Nesse contexto, a expansão horizontal, e ao mesmo tempo vertical, dos sistemas educacionais reflete as características de desigualdade da sociedade. A mesma educação não chega a todos igualmente, e, também, nem sempre a educação oferecida corresponde às demandas e necessidades dos diversos grupos sociais, culturais e étnicos (CAMPOS, 2013, p.25).

Surgem no Brasil, a partir deste contexto, os sinais mais claros da influência neoliberal na educação, o processo de privatização da educação brasileira, cujo mercado deveria substituir o papel do Estado como provedor da educação pública. Esta proposta devolve ao indivíduo, segundo os neoliberais, o poder de decisão econômica e social e garantiria a eficácia das instituições públicas desgastadas pela ineficiência da gerência do Estado, incentivando a privatização dos setores públicos, reduzindo os gastos com as políticas públicas, sobremodo, o incentivo a livre competição do mercado.

No final da década de 80 foi aprovada a nova Constituição Federal (1988) que representou um marco em termos de democracia na vida dos brasileiros, uma vez que trata da garantia de direitos, nomeadamente a saúde, a moradia, a educação, a alimentação entre outros. Na seção 1 no seu artigo 205, que trata da educação, afirma que esta deve ser concebida como direito de todos e dever do Estado e da família, será promovida e incentivada com a colaboração da sociedade, visando ao pleno desenvolvimento da pessoa, seu preparo para o exercício da cidadania e sua qualificação para o trabalho [...] e no artigo IV, que trata da garantia do direito ao atendimento em creche e pré-escola às crianças de zero a seis anos de idade, complementando a ação da família.

Porém, contrariando essa perspectiva, assim como os demais países da América Latina e muitos de outros continentes, o Brasil adota as políticas de ajuste econômico que impõem restrições as políticas sociais, em conformidade com as predeterminações do Neoliberalismo. Nessa condição, a qualidade da educação se incorpora à agenda do debate educacional no contexto das reformas educativas, caracterizadas como neoliberais. Reformas influenciadas, sobretudo, por agências multilaterais - Banco Mundial, Organização das Nações Unidas para a Educação, a Ciência e a Cultura - UNESCO, Organização das Nações Unidas - ONU e outras, num contexto de controle, de restrição de políticas sociais e de privatização das políticas públicas incluindo as de educação (BAUMAN, 2000, p.65).

Revista de Administração Educacional, Recife, V. 1 . № 1 . 2017 jan./jun. 2017 p.52-66 
Nesse período, a qualidade é concebida como mera busca de eficiência, a preocupação do Estado era promover o melhor desempenho da educação com redução dos gastos, poucos recursos, muitas metas. Na ocasião do governo do Presidente Fernando Henrique Cardoso essa preocupação se tornou hegemônica, o lema: “O Brasil não gasta pouco em educação, mas gasta mal”, ficou conhecido. Segundo Nascimento e Marques (2015, p. 78), esse lema, oriundo da área empresarial, entrou no campo educacional e, assim, as técnicas empresariais e a qualidade total foram adotadas efetivamente nas redes de ensino públicas do país.

Na década de 1990, começa a produção na área acadêmica de um discurso que critica a transposição da lógica de mercado para área educacional. Para os teóricos, essa lógica estimula a competição entre escolas; a remuneração de professores e professoras por resultados; as famílias são concebidas como "consumidoras" ou "clientes". Para Nascimento e Marques (2015, p.78) o produto agora é o principal resultado (notas em exames padronizados, alunos aprovados no vestibular, fluxo escolar), e os cálculos são feitos com base no custo versus retorno econômico, tendo como referência os postulados da teoria do capital humano disseminados pelos técnicos do Banco Mundial. Entram em cena os grandes sistemas de avaliação, baseados em testes padronizados que não consideram o contexto das escolas. Nessa concepção, os direitos sociais conquistados com Constituição perdem a força e a tendência é de não efetivação.

Neste contexto, segundo Campos (2013, p,25), observa-se um deslocamento das preocupações com a democratização do acesso para ênfase na qualidade da Educação com foco na quantidade, e, acompanhando esta lógica, é visível a crescente presença de crianças, adolescentes e jovens das camadas mais pobres nas escolas públicas. É inegável que nesse período houve uma significativa expansão de matrículas em todos os países do mundo, inclusive no Brasil, principalmente nos ensinos primários e secundários, mas, também, de crianças em idade pré-escolar.

Essa expansão vai refletir as desigualdades sociais, uma vez que a qualidade da educação que chega para uns não é a mesma para todos e, também, o caráter da educação oferecida não atende as demandas e necessidades dos diversos grupos sociais e culturais. Para Casassus (2002, p. 50), com as reformas educativas da década de 1990 "ao substituir o discurso e as políticas de igualdade de oportunidades pelo discurso e políticas da qualidade" dissociou-se a questão da qualidade de uma política de igualdade.

Para Campos (2013, p.25), as reformas educativas trouxeram consigo a implantação dos sistemas nacionais e internacionais de avaliação dos resultados de aprendizagem medidos 
por testes aplicados aos alunos das escolas primárias e secundárias, disponibilizando uma grande quantidade de dados e incentivos de comparações entre escolas, cidades, regiões e países. A qualidade da educação passou a ser definida principalmente por estes indicadores, os quais afirmaram, com base em critérios que ganharam grande legitimidade pública, as diferenças sociais entre os alunos: estudantes de escolas privadas obtêm, geralmente, melhores resultados do que aqueles matriculados em escolas públicas; quem habita regiões mais desenvolvidas alcança melhores resultados do que alunos de regiões mais pobres, especialmente zonas rurais; os grupos étnico-raciais discriminados têm os piores resultados.

Nesses termos, as reformas educacionais, ao incidirem sobre realidades bastante diversas, sobre grupos sociais com diferentes condições de vida e diferentes possibilidades de exercício de poder, sobre sociedades profundamente divididas nos planos, econômico, social, político e cultural, não produziram resultados que levassem a uma maior democratização do acesso ao conhecimento e a uma melhor resposta da escola às necessidades dos segmentos da população.

Em meio a essas contradições, mais especificamente, ao descompasso entre as metas das reformas, as prioridades econômicas do governo e a disponibilidade de recursos públicos, fez com que o tema da qualidade ganhasse centralidade baseada na concepção e no modelo de eficiência gerencial - fundamentada na lógica do mercado transposta para área educacional, onde os cálculos dos gastos com a educação são feitos com base no custo versus retorno econômico, tendo como referência os postulados da teoria do capital humano disseminados pelos técnicos do Banco Mundial (SOARES, 2002, p.25).

As consequências geradas por este modelo levaram à promoção de níveis e de modalidades de ensino e acesso ao conhecimento diferenciado, gerando desigualdades entre alunos de origens sociais díspares. Além disso, condicionou a terceirização e a privatização dos serviços educacionais, bem como a focalização dos recursos da educação para as classes pobres e miseráveis em lugar da universalização garantida pela Constituição e a descentralização dos serviços educativos, sem a garantia de recursos materiais, humanos e, muitas vezes, sem condições políticas de controle social.

Segundo Campos (2013, p.26), é, todavia, importante reconhecer que as reformas, com todas suas limitações e contradições, tiveram o mérito de ajudar a incluir a educação na agenda política e dar visibilidade social as contradições antes restritas ao campo específico de atuação dos educadores. Isto porque a massa de dados gerada pelos sistemas de avaliação centralizados possibilitou a realização de estudos que puseram a nu as desigualdades do 
acesso ao conhecimento por parte de alunos com diferentes origens sociais, evidenciando processos de discriminação e de esforços de desigualdades que persistem na escola até os dias atuais, agora aparentemente abertos a todos.

No final da década de 1990, mais especificamente, no último ano, brota a Campanha Nacional pelo Direito a Educação impulsionada por um conjunto de organizações da sociedade civil, no contexto preparatório do processo para a Cúpula Mundial de Educação, realizada em Dacar, no Senegal, em 2000. Segundo Carreira e Pinto (2007, p. 73), a articulação surge com o desafio de somar diferentes forças políticas pela efetivação dos direitos educacionais garantidos por lei, que determina que todo cidadão e toda cidadã tenham acesso a uma educação pública de qualidade. Nessa direção, a Campanha visa disseminar amplamente o conceito de educação enquanto direito social, focalizando a qualidade, o financiamento e a gestão democrática da educação, assim como a valorização de seus profissionais (CAMPOS, 2006, p. 13).

Em 1990, realizou-se em Jomtien - Tailândia - a Conferência Mundial de Educação para Todos, que definiu um amplo conjunto de desafios a serem enfrentados de modos diversos pelos sistemas educacionais ao redor do mundo.

Como consequência dessa conferência, em 2000, 164 países, inclusive o Brasil, se reuniram em Dakar-Senegal na chamada global à ação Cúpula Mundial de Educação para avaliar as metas estabelecidas na Conferência Mundial de Educação e propor uma agenda comum de políticas de Educação para Todos (EPT) visando o fortalecimento da cidadania e à promoção de habilidades necessárias a um desenvolvimento humano pleno e sustentável. Nessa reunião, foram acordados seis objetivos a serem perseguidos por todos os países signatários tendo em vista prover os meios para melhorar as condições de vida de crianças, jovens e adultos por meio da educação para todos, gratuita e com a garantia da qualidade. Tais objetivos estão relacionadas ao cuidado e à Educação Infantil; ao Ensino Fundamental universal; ao desenvolvimento de habilidades de jovens e adultos; à alfabetização de adultos; à paridade e à igualdade de gênero; e à qualidade da educação (BRASIL, 2014, p. 7-9):

a) expandir e melhorar o cuidado e a educação das crianças pequenas, especialmente para as crianças mais vulneráveis e em maior desvantagem;

b) assegurar que todas as crianças, especialmente meninas e crianças em circunstâncias difíceis, tenham acesso à Educação Primária obrigatória, gratuita e de boa qualidade até o ano 2015;

Revista de Administração Educacional, Recife, V. 1 . № 1 . 2017 jan./jun. 2017 p.52-66 
c) assegurar que as necessidades de aprendizagem de todos os jovens e adultos sejam atendidas pelo acesso equitativo à aprendizagem apropriada, por habilidades para a vida e por programas de formação para a cidadania;

d) alcançar melhoria de 50\% nos níveis de alfabetização de adultos até 2015;

e) eliminar disparidades de gênero na Educação Primária e Secundária até 2005 e alcançar a igualdade de gênero na educação até 2015, com ênfase na garantia ao acesso e no desempenho pleno e equitativo de meninas na Educação Básica de boa qualidade;

f) melhorar todos os aspectos da qualidade da educação e assegurar excelência para todos, de forma a garantir a todos resultados reconhecidos e mensuráveis, especialmente na alfabetização, na matemática e habilidades essenciais à vida.

Ao assumir tais objetivos, o Brasil passou a integrar o conjunto de países empenhados na conquista das metas de Educação Para Todos com a garantia de ser gratuita de qualidade. A proposta, conforme encaminhamentos do Compromisso de Dakar, é que haja engajamento efetivo do Brasil, no sentido de propor mudanças importantes no perfil das políticas públicas desenvolvidas no país.

Os resultados destas mudanças foram apresentados por cada país no Fórum Mundial de Educação (World Education Forum - WEF 2015), entre os dias 19 e 22 de maio, em Incheon, na Coréia do Sul, organizado pela UNESCO, com a participação de mais de 130 Ministros de Educação e mais de 1.500 participantes, entre organizações de sociedade civil, agências bilaterais e multilaterais, professores, ativistas e experts.

Nesses termos, o Fórum acordou a nova agenda da educação, que irá vigorar entre 2015 e 2030, com os novos objetivos que compõem o compromisso Educação para Todos, iniciado em 1990, na Conferência de Jomtien, e reiterado em 2000, no Fórum Mundial de Educação realizado em Dakar.

Reconhecendo que estão longe de alcançar a educação para todos, a nova agenda, através da Declaração de Incheon, afirma a importância da educação como principal impulsionador do desenvolvimento e reforça o compromisso de "garantir educação inclusiva, equitativa e de qualidade e de promover oportunidades de educação e aprendizagem ao longo da vida para todos".

Na perspectiva de efetivar uma educação de qualidade para todos, a Declaração de Incheon (2015, p. 2) compromete-se com a garantia da promoção de uma educação de qualidade, com a melhoria dos resultados de aprendizagem, com o reforço de insumos e de processos, com a avaliação dos resultados de aprendizagem e com a garantia dos mecanismos

Revista de Administração Educacional, Recife, V. 1 . № 1 . 2017 jan./jun. 2017 p.52-66 
de mensuração do progresso. Ademais, garante que professores e educadores sejam empoderados, recrutados adequadamente, bem capacitados, qualificados profissionalmente, motivados e apoiados em sistemas que disponham de bons recursos e sejam eficientes e dirigidos de maneira eficaz.

\section{CONSIDERAÇOES FINAIS}

A análise do contexto sócio histórico e cultural da construção do conceito de qualidade e de qualidade da educação, apresentado por estudiosos da área, clássicos e contemporâneos, a partir de diferentes perspectivas e situações, mostra que conforme as exigências da sociedade, estes conceitos vão se alterando, adquirindo significados inerentes a cada época.

A análise mostra que a partir dos anos de 1990, surge o movimento pela efetivação dos direitos educacionais garantidos nos termos da lei e que determina que todo cidadão e toda cidadã tenham acesso a uma educação pública de qualidade. Verifica-se a inclusão do conceito de qualidade no campo da educação como direito social em diversos documentos, focalizando a democratização da qualidade da educação como direito de todos e não de poucos.

Porém, o que se constata é que o cumprimento do que se propõe nos termos da lei não foi concretizado, embora se admita que resultados moderados foram alcançados nesses quinze anos. As desigualdades na educação não foram suficientemente trabalhadas e as crianças mais pobres permanecem sujeitas à exclusão escolar e a uma baixa qualidade de ensino (UNESCO, 2015). Como resultado, segundo a PNAD (2014), 2,9 milhões de crianças e adolescentes entre 4 e 17 anos, período que compõe a educação básica obrigatória de acordo com a legislação nacional, estão fora da escola, e apenas 55,2\% da população entre 15 e 17 anos está matriculada no ensino médio. Além disso, o Brasil está entre as 10 nações responsáveis por $72 \%$ da população mundial de analfabetos, com 13 milhões de pessoas com 15 anos ou mais que não sabem ler (UNESCO, 2015).

Considera-se ainda, que, se os impasses e limitações apontados neste estudo para uma efetiva melhoria da qualidade da educação não puderem ser traduzidos em medidas práticas e concretas, no sentido de reduzir a distância entre a legislação e sua efetivação, o debate da qualidade da educação construído numa perspectiva democrática, comprometida com as transformações sociais e com a melhoria da qualidade da educação para todos, não se traduzirá em mudanças efetivas nas políticas educacionais.

Revista de Administração Educacional, Recife, V. 1 . № 1 . 2017 jan./jun. 2017 p.52-66 
Isto porque a qualidade da Educação exige condições materiais, recursos financeiros, insumos, diretamente relacionados a melhoria da infraestrutura física, organizacional e funcional das instituições escolares. Exige à valorização urgente dos/as profissionais de educação; à existência de materiais didáticos e paradidáticos; à garantia de condições não somente de acesso, mas de permanência, desenvolvimento integral dos sujeitos de direito usuários/as dos produtos e dos serviços de consumo coletivo educacionais.

\section{REFERENCIAS}

AILDEFONSO, E. Gestão da Qualidade. Centro Federal de Educação Tecnológica, v.1, Espirito Santo, 2006.

ALVES, A. A. Qualidade Total x Qualidade Social: Duas Correntes Dicotômicas na Educação Pública do Rio Grande do Sul no Início do Século XXI. IX AMPED Sul, Seminário de Pesquisa em Educação da Região Sul, 2012.

BAUMAN, Z. Modernidade líquida. Rio de Janeiro: Zahar, 2000.

BRASIL. Constituição da República Federativa do Brasil: promulgada em 5 de outubro de 1988. Brasília, DF: Senado Federal/Centro Gráfico, 1988.

BRASIL. Plano Nacional de Educação. 2001. Acessado em: 27/07/2014. Disponível em http://portal.mec.gov.br/arquivos/pdf/pne.pdf.

CAMPOS, M. M.; FÜLLGRAF, J. ; WIGGERS, V. Qualidade da Educação Infantil Brasileira: Alguns Resultados de Pesquisa. Cadernos de Pesquisa, v. 36, n. 127, jan./abr. 2006.

CAMPOS, M. M. Entre as políticas de qualidade e a qualidade das práticas. Cadernos de Pesquisa. v.43 n.148 p.22-43 jan./abr. 2013.

CARREIRA, D.; PINTO, J. M. R. Custo Aluno - Qualidade Inicial: rumo a educação pública de qualidade no Brasil. São Paulo: Global: Campanha Nacional pelo Direito a Educação, 2007.

CASASSUS, J. Cambios paradigmáticos en educación. Revista Brasileira de Educação, N ${ }^{\circ}$ 20, Maio/Jun/Jul/Ago 2002.

CHIAVENATO, I. Introdução à teoria geral da administração: uma visão abrangente da moderna administração das organizações. 7. Ed. Rio de Janeiro: Elsevier, 2003.

GENTILI, P.; SILVA, T. T. Neoliberalismo, qualidade total e educação: visões críticas. $2^{\text {a }}$ ed. Petrópolis, 2015.

HARGREAVES, A. O Ensino na Sociedade de Conhecimento: educação na era da insegurança. Tradução de Roberto Cataldo Costa. Porto Alegre: Artmed, 2007.

HERÉDIA, V. B. M. Dilemas da globalização. In: Qualidade em educação: um debate necessário. Passo Fundo: Universidade Educação Básica. Série Interinstitucional, 1997.

MAXIMIANO, A. C. A. Introdução à Administração. 4. ed. São Paulo: Atlas, 1995.

Revista de Administração Educacional, Recife, V. 1 . № 1 . 2017 jan./jun. 2017 p.52-66 
NASCIMENTO, J.A; MARQUES, L.R. Por uma qualidade da educação no semiárido. Rev. Pensamento Plural, Pelotas [16]: 75 - 104, janeiro-junho 2015.

UNESCO. Organização das Nações Unidas para a educação, a ciência e a cultura, Educação para todos: http://www.unesco.org/new/en/education/themes/leading-the.

internationalagenda/education-for-all/education-post-2015.

Pesquisa Nacional por Amostra de Domicílios - Indicadores Sociais Educação 2014:

http://downloads.ibge.gov.br/downloads_estatisticas.htm

UNICEF. Fundo das Nações Unidas para a Infância, Relatório Situação Mundial da Infância, UNICEF, Nova Iorque, 2008.

https://www.unicef.org/publications/files/SOWC_2015_Summary_Portuguese_Web.pdf 1998.

ZITKOSKI, J. J. Educação de qualidade: que qualidade queremos? In: Qualidade em educação: um debate necessário. Passo Fundo: Universidade Educação Básica. Série Interinstitucional, 1997. 